\title{
The Atlantic ITCZ bias in CMIP5 models
}

\author{
Angela Cheska Siongco $\cdot$ Cathy Hohenegger • \\ Bjorn Stevens
}

Received: 10 June 2014 / Accepted: 6 October 2014 / Published online: 4 November 2014

(C) The Author(s) 2014. This article is published with open access at Springerlink.com

\begin{abstract}
Precipitation over the tropical Atlantic in 24 atmospheric models is analyzed using an object-based approach, which clusters rainy areas in the models as precipitation objects and calculates their properties such as size, amplitude, and location. Based on the distribution of precipitation objects over land and over ocean, two classes of models emerge. The first class of models has a reasonable representation of objects over land but misplaces the ocean object westward, near the coast of Brazil, instead of the central Atlantic as observed. The second class of models show small-sized objects over land with intense precipitation values; for these models, the ocean object is located eastward, near the coast of Guinea. The Atlantic intertropical convergence zone structure in the models exhibits either the West or the East Atlantic bias. No model matches the observed precipitation distribution. The two distinct model behaviors in the mean state are traced to the coastal precipitation bias of the models in boreal spring. In this season, the two model groups place the main precipitation object on opposite coasts-one group puts it at the south coast of Brazil and the other group places it at the Gulf of Guinea. This west-east partitioning of precipitation is sustained in boreal summer, resulting in the West and East Atlantic bias in the annual mean. It is found that models with the East Atlantic bias tend to be high resolution models which rain excessively over the Gulf of Guinea starting from boreal spring.
\end{abstract}

Keywords GCM biases · Precipitation · Tropical Atlantic $\cdot$ Resolution

A. C. Siongco $(\bowtie) \cdot C$. Hohenegger · B. Stevens

Max Planck Institute for Meteorology, Bundesstrasse 53, 20146 Hamburg, Germany

e-mail: angela-cheska.siongco@mpimet.mpg.de

\section{Introduction}

The tropical Atlantic circulation is largely controlled by land-ocean interactions involving the continents, Africa and South America, and the Atlantic basin in between. Sea surface temperature (SST) modulates the seasonal cycle of rainfall and its interannual variability in key areas such as the Amazonia and West Africa (Mitchell and Wallace 1992; Zebiak 1993; Okumura and Xie 2004; Yin et al. 2012). Orographic features like the Atlas-Ahaggar mountains in north Africa induce changes in the large-scale circulation and influence the location of the intertropical convergence zone (ITCZ) (Sultan and Janicot 2003; Cook et al. 2004; Hagos and Cook 2005). Because the circulation depends on such coupled processes, simulating the tropical Atlantic climate remains a challenge for climate models. For instance, most coupled general circulation models (GCMs) show a reversed SST gradient along the equator, with an anomalously warm SST in the east and cold SST in the west (Richter et al. 2013). This reversed SST gradient is a result of the westerly wind bias originating from the atmospheric component of the models, and persists even in high-resolution models (Chang et al. 2007; Richter and Xie 2008; Richter et al. 2012, 2013; Patricola et al. 2012; ZermenoDiaz and Zhang 2013). Using the diagnostic framework developed by Stevens et al. (2002), Zermeno-Diaz and Zhang (2013) deduced that the westerly wind bias over the equatorial Atlantic ocean was a result of insufficient mixing of momentum into the boundary layer and erroneous sea level pressure (SLP) gradient. The latter is linked to precipitation biases in the atmospheric component which are exacerbated in coupled simulations (Richter and Xie 2008; Chang et al. 2008; Richter et al. 2013).

Despite continued model improvement, precipitation biases over the tropical Atlantic persist in current GCMs in 
their coupled as well as uncoupled mode. Previous studies have shown that some models exhibit common biases in this area such as the overestimation of precipitation in the Southern hemisphere, the rainfall excess in the Caribbean, and the Amazonian dry bias during boreal summer (Davey et al. 2002; Biasutti et al. 2006; Stockdale et al. 2006; Yin et al. 2012). An explanation for the tropical Atlantic precipitation bias has been provided by Biasutti et al. (2006). Using a set of six atmospheric GCMs, they showed that in contrast to observations, models collocate precipitation and SST. This leads to excessive precipitation south of the equator during boreal spring and in the Caribbean sector during summer. The models' apparent oversensitivity to SST is amplified by their lack of sensitivity to atmospheric humidity. The robustness of this result has not been tested with a larger ensemble of models and it remains unclear whether oversensitivity to SST is indeed the root cause of most model biases. In fact, there is a shortage of studies which try to identify atmospheric controls on tropical Atlantic precipitation.

This study aims to fill this gap by considering a larger ensemble of atmosphere-only models and by investigating controls on the precipitation distribution in each ensemble member. Focus is set on identifying and explaining robust precipitation biases across the models which are less likely to be influenced by the particular design of a model. Detailed consideration of the structure of precipitation simulated by each model is performed through an object-based method. The role of model sensitivity to SST and other factors which control the structure of the Atlantic ITCZ are explored in order to explain the results of the object-based analysis.

The paper is organized as follows: Sect. 2 describes the datasets and the object-based method for precipitation analysis. Section 3 presents the results of the object-based analysis in terms of the mean state and seasonal cycle of precipitation. Section 4 discusses possible controls on the Atlantic ITCZ structure, explaining the results of Sect. 3. Conclusions are given in Sect. 5.

\section{Methods}

\subsection{Description of the datasets}

In this study, precipitation is analyzed from 22 atmosphereonly models under the Coupled Model Intercomparison Project Phase 5 (CMIP5). The models are run with prescribed SSTs from observations following an Atmospheric Model Intercomparison Project (AMIP) style of integration (Gates 1992). Monthly output of model precipitation covering the period 1979-2008 is used. In addition to the CMIP5 models, two high resolution versions of the MPI model under the German consortium project STORM/AMIP are
Table 1 Description of models used in this study with information on resolution and deep convection scheme

\begin{tabular}{|c|c|c|c|}
\hline Model name & nLon & Deep convection scheme & Class \\
\hline ACCESS1.0 & 192 & $\begin{array}{l}\text { Gregory and Rowntree } \\
\text { (1990) }\end{array}$ & West Atl \\
\hline BCC-CSM1 & 128 & Zhang and Mu (2005) & East Atl \\
\hline BNU-ESM & 128 & Zhang and McFarlane (1995) & West Atl \\
\hline CanAM4 & 128 & Zhang and McFarlane (1995) & East Atl \\
\hline CESM(CAM5) & 288 & Zhang and McFarlane (1995) & East Atl \\
\hline CCSM4 & 288 & Zhang and McFarlane (1995) & East Atl \\
\hline CMCC-CM & 480 & $\begin{array}{l}\text { Tiedtke (1989)/Nordeng } \\
\text { (1994) }\end{array}$ & East Atl \\
\hline CNRM-CM5 & 256 & Bougeault (1985) & East Atl \\
\hline CSIRO-Mk3.6.0 & 192 & $\begin{array}{l}\text { Gregory and Rowntree } \\
\text { (1990) }\end{array}$ & East Atl \\
\hline EC-EARTH & 320 & $\begin{array}{l}\text { Fritsch and Chappell } \\
\text { (1980)/Nordeng (1994) }\end{array}$ & West Atl \\
\hline FGOALS-s2 & 128 & $\begin{array}{l}\text { Tiedtke (1989)/Nordeng } \\
\text { (1994) }\end{array}$ & East Atl \\
\hline GISS-E2-R & 144 & $\begin{array}{l}\text { Gregory (2001)/Del Genio } \\
\text { et al. (2007) }\end{array}$ & West Atl \\
\hline GFDL-HIRAM-C180 & 576 & Bretherton et al. (2004) & East Atl \\
\hline GFDL-CM3 & 144 & $\begin{array}{l}\text { Donner (1993)/Wilcox and } \\
\text { Donner (2007) }\end{array}$ & West Atl \\
\hline HADGEM2-A & 192 & $\begin{array}{l}\text { Gregory and Rowntree } \\
\text { (1990) }\end{array}$ & West Atl \\
\hline INMCM4 & 180 & Betts and Miller (1986) & West Atl \\
\hline IPSL-CM5A-LR & 96 & Emanuel (1991) & West Atl \\
\hline IPSL-CM5B-LR & 96 & Bony and Emanuel (2001) & West Atl \\
\hline MIROC5 & 256 & $\begin{array}{l}\text { Chikira and Sugiyama } \\
\text { (2010) }\end{array}$ & East Atl \\
\hline MPI-ESM-LR & 192 & $\begin{array}{l}\text { Tiedtke (1989)/Nordeng } \\
\text { (1994) }\end{array}$ & West Atl \\
\hline MPI-ESM-HR & 384 & $\begin{array}{l}\text { Tiedtke (1989)/Nordeng } \\
\text { (1994) }\end{array}$ & West Atl \\
\hline MPI-ESM-XR & 768 & $\begin{array}{l}\text { Tiedtke (1989)/Nordeng } \\
\text { (1994) }\end{array}$ & West Atl \\
\hline MRI-AGCM32H & 640 & Yukimoto et al. (2011) & East Atl \\
\hline NorESM1-M & 144 & Zhang and McFarlane (1995) & West Atl \\
\hline
\end{tabular}

The model classification in the last column is discussed in Sect. 3

examined (Stevens et al. 2013). Table 1 lists the models included in this study together with their respective resolution (indicated by nLon, the number of gridpoints along the equator) and reference for their deep convection scheme. All models employ a mass-flux type of parameterization except for INMCM4, which uses a convective adjustment scheme. All data are interpolated to a fixed lat-lon grid with 96 gridpoints in latitude and 192 in longitude, equivalent to a grid of $1.875^{\circ}$. The study covers the tropical Atlantic sector, which is defined here as the domain encompassing $90^{\circ} \mathrm{W}-45^{\circ} \mathrm{E}, 30^{\circ} \mathrm{S}-30^{\circ} \mathrm{N}$. This includes the continents South America, Africa and the tropical Atlantic basin. 

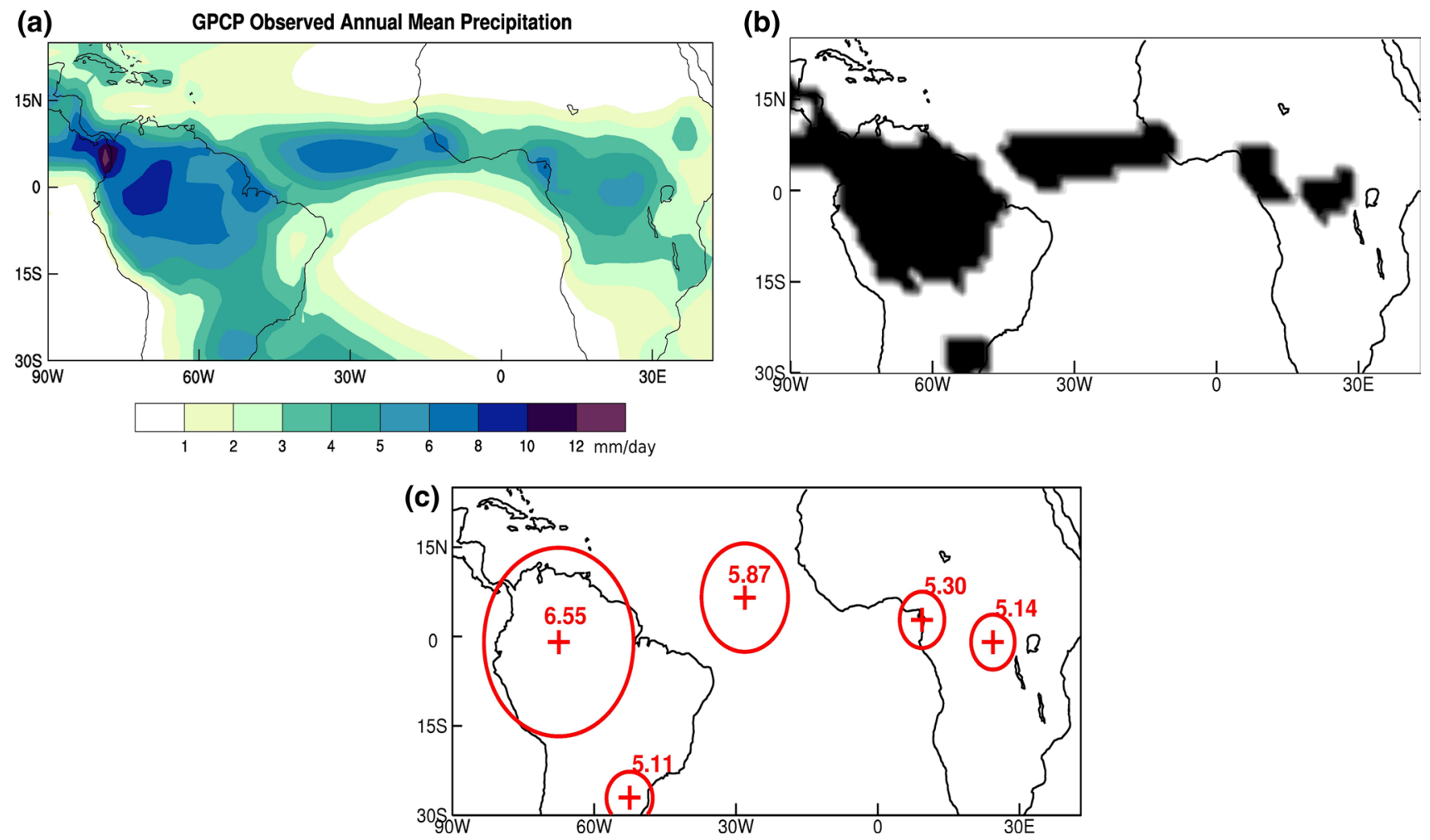

Fig. 1 From the a original precipitation field, a threshold $P_{f}$ is set and only $\mathbf{b}$ gridpoints with precipitation values $P>P_{f}$ are considered to get c precipitation objects with properties such as size (circle), amplitude (numbers), and location (cross)

Precipitation from the AMIP models is compared with three observational data sets: the Global Precipitation Climatology Project (GPCP) version 2 (Adler et al. 2003), the Tropical Rainfall Measuring Mission (TRMM) product 3B-42 (Huffman et al. 2007), and the Hamburg Ocean Atmosphere Parameters and Fluxes from Satellite Data (HOAPS) version 3 (Andersson et al. 2010). The GPCP dataset is a combination of satellite and rain gauge data and covers the period $1979-2010$ with a $2.5^{\circ}$ spatial resolution. Precipitation data from TRMM is a merged product of high quality microwave and infrared precipitation and rootmean-square precipitation error estimates. It covers the period $1998-2010$ with a $0.25^{\circ}$ spatial resolution. HOAPS only gives data for ocean points and is used as a supplementary dataset to GPCP and TRMM over the tropical Atlantic ocean. It covers the period 1987-2005 with a $0.5^{\circ}$ spatial resolution. All observational data are interpolated to the same model grid as is used to analyze the model results.

\subsection{Object-based approach for analyzing precipitation distribution}

Comparing precipitation between models and observations is usually performed through gridpoint-based measures such as root-mean-square error (RMSE) analysis. This gives information on where the model overestimates or underestimates the amplitude of precipitation with respect to observed values. However, precipitation is not only characterized by amplitude but it takes on a complex structure as well. A gridpoint-based evaluation of precipitation is susceptible to the double penalty problem, where a model with correct amplitude and structure of precipitation but with a slight displacement in its position is rated as a lowscore model. Such a model would be rated as poorly as another model which did not get the precipitation event at all (Wernli et al. 2008). To circumvent the double penalty problem and to extract more meaningful information from the model, object-based measures in evaluating precipitation distribution have been proposed (Ebert and McBride 2000; Davis et al. 2006; Wernli et al. 2008). Instead of comparing precipitation values gridpoint by gridpoint, the original precipitation field is condensed into precipitation objects. The object identification procedure is illustrated in Fig. 1. A threshold $P_{f}$ is set and only gridpoints with precipitation values $P>P_{f}$ are considered. These remaining gridpoints are then clustered into objects described by their structure, amplitude, and location, also known as SAL (Wernli et al. 2008). This allows for a three-dimensional quality measure of model performance. The SAL method has been originally developed for high-resolution weather 

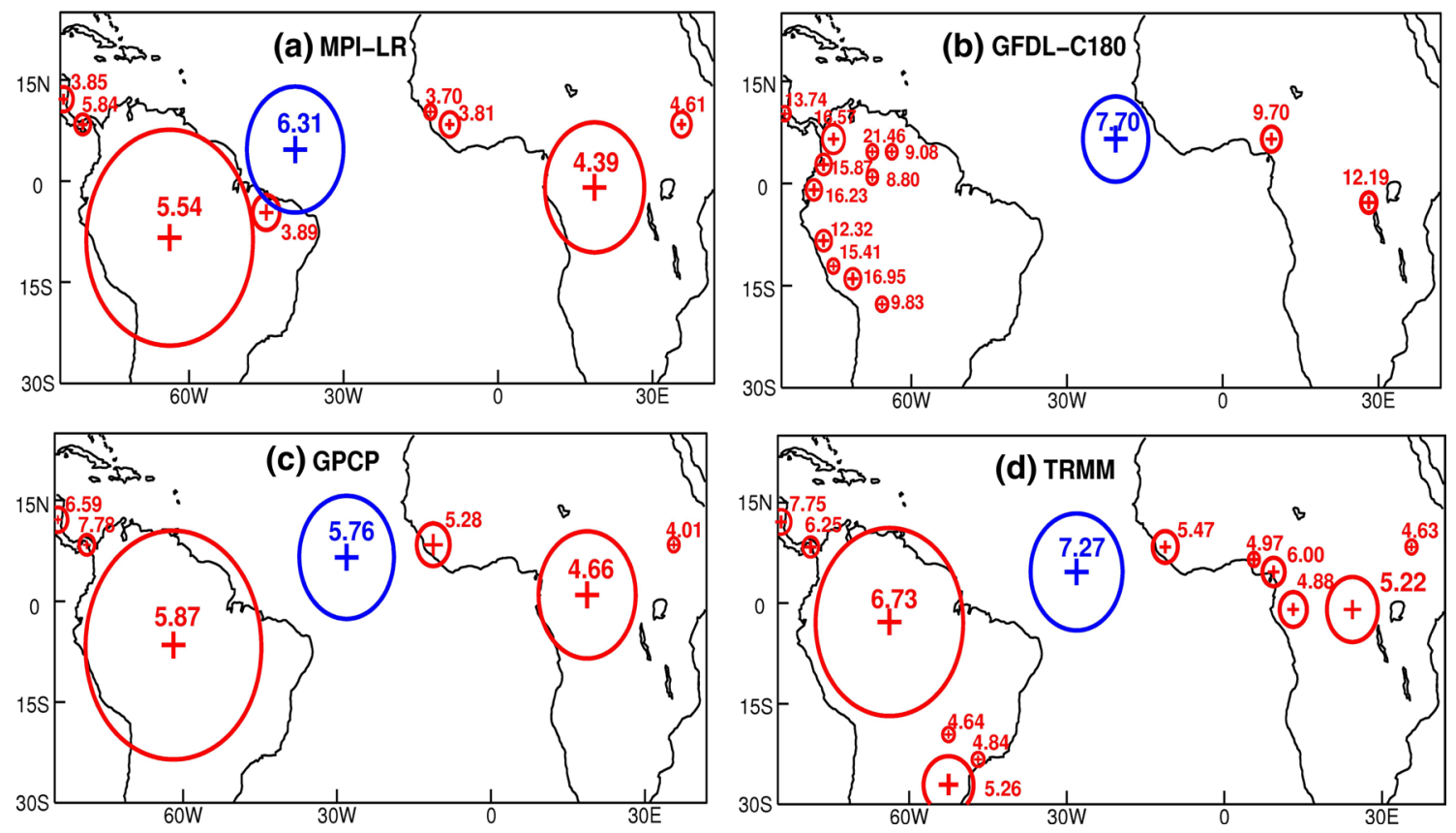

Fig. 2 Land and ocean precipitation objects from two models, a MPI-LR and b GFDL-C180, and observations, c GPCP and d TRMM. Land objects are marked in red and ocean objects in blue.

forecasts (Gilleland et al. 2009; Ebert and Gallus 2009) but has recently been proven useful for assessing low-resolution climate simulations (Hohenegger and Stevens 2013).

In this study, the threshold is set as: $P_{f}=f \cdot P_{\max }$ where $P_{\max }$ is the maximum precipitation value of a model over a certain area and $f$ is a fraction of this value. Note that $P_{\max }$ is not an absolute reference value but instead depends on the model. The objects essentially represent regions where the model prefers to rain. Since precipitation differs between land and ocean, with stronger and more peaked precipitation over land, different thresholds are chosen for land and oceanic sectors. Hereafter, land and ocean terms will be denoted by the subscripts $l$ and $o$, respectively. For the mean state precipitation over land, $P_{f l}=0.35 \cdot P_{\operatorname{maxl}}$ while for oceanic precipitation $P_{f o}=0.60 \cdot P_{\operatorname{maxo}}$. To capture the seasonal cycle of the multimodel mean, the fraction $f_{o}$ is increased to 0.70 when considering seasonal averages. As pointed out by Wernli et al. (2008), there is no objective criteria for the choice of $f_{l}$ and $f_{o}$ but a general rule is that if the fractions are well-chosen, the resulting precipitation objects should be consistent with features which can be seen by eye. This is the case with the chosen thresholds. Note that if the threshold is too high, robust precipitation features cannot be captured because the objects will be too sensitive to sharp peaks (one or two pixels of very intense rainfall). On the other hand, if the threshold is too low, the objects will not be sensitive enough to capture distinct features of precipitation. The model classification described in
The cross marks the weighted centroid, the circle shows the equivalent area, and the numbers indicate the mean intensity of the precipitation object

the next sections are found to be robust even if other thresholds are used, ranging from 50 to $70 \%$.

After setting the thresholds $P_{f l}$ and $P_{f o}$, land and ocean precipitation objects are identified. For each object, a set of three properties is calculated: (1) Size, the number of pixels comprising the object, (2) Amplitude, the mean intensity of the pixels of the object, and (3) Location, the coordinates of the weighted centroid of the object. To capture the observed precipitation structure in the central Atlantic as seen in Fig. 1a, it is practical to identify the main ocean object as the largest object. Precipitation features near the coasts are found to be insensitive to the land-ocean separation implemented here. The results discussed in the succeeding sections are robust even when taking a larger area for the ocean to include the equatorial coastal regions.

\section{Representing tropical Atlantic precipitation}

\subsection{The mean state}

The ability of models to represent the mean state of precipitation over the Atlantic sector is assessed using the previously described object-based approach. By doing so, two classes of models emerge. Figure 2 illustrates the two classes of model behavior using MPI-LR and GFDL-C180 as examples. The MPI-LR has a reasonable representation of the distribution of objects over land, with comparable 
Fig. 3 Longitude of the ocean object plotted against the intensity-area ratio (measure of peakedness) averaged over the three most rainy objects over land. The gray lines in GPCP and TRMM show the interquartile range of the interannual variability of their object properties

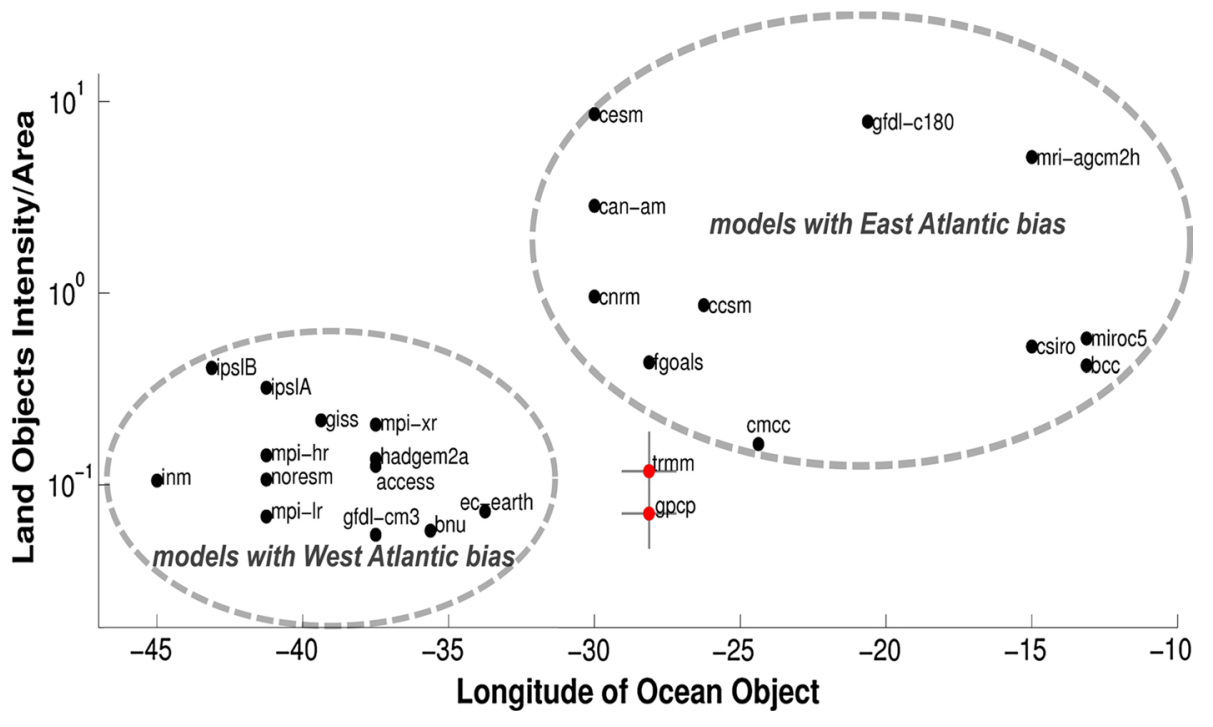

properties to objects in the observed precipitation field. The ocean object, however, is misplaced too far west, near the coast of Brazil. The GFDL-C180 model shows small-sized land objects with very high precipitation values. These land objects are located in regions with pronounced relief in the terrain, especially over the Andes in South America. For GFDL-C180, the oceanic precipitation structure is more longitudinally distributed, with the ocean object located near West Africa, hence too far east. It is noteworthy that over ocean, neither MPI-LR nor GFDL-C180 matches the observed precipitation distribution. GPCP and TRMM place the main object in the central Atlantic $\left(28.125^{\circ} \mathrm{W}\right)$. HOAPS also has a central ocean object located at $30^{\circ} \mathrm{W}$ (not shown). The models place the ocean object either too far west (MPI-LR) or too far east (GFDL-C180). Further examination of the two models indicate that this behavior is evident in the individual years of the simulation. The MPI-LR ocean object has a mean location of $41.25^{\circ} \mathrm{W}$ with an interquartile range of $\pm 1.875^{\circ}$ across the years while the GFDL-C180 ocean object at $20.62^{\circ} \mathrm{E}$ varies by $\pm 3.75^{\circ}$ across the years. Over land, GFDL-C180 does not reproduce the observed land objects and instead shows peaked precipitation objects. This is because GFDL-C180 has a very strong $P_{\operatorname{maxl}}$, and thus a high threshold $P_{f l}$, preventing the object identification algorithm to pick out the land objects seen in observations and in MPI-LR. The object identification algorithm emphasizes the fact that GFDL-C180 has a very different representation of land precipitation over Africa and South America as compared to observations or MPI-LR due to excessive production of orographic precipitation. Because of its higher spatial resolution, TRMM has four objects over equatorial Africa while GPCP clusters these features as one big object. Even so, the amplitude of the TRMM objects over Africa is not nearly as high as the two peaked objects in GFDL-C180.

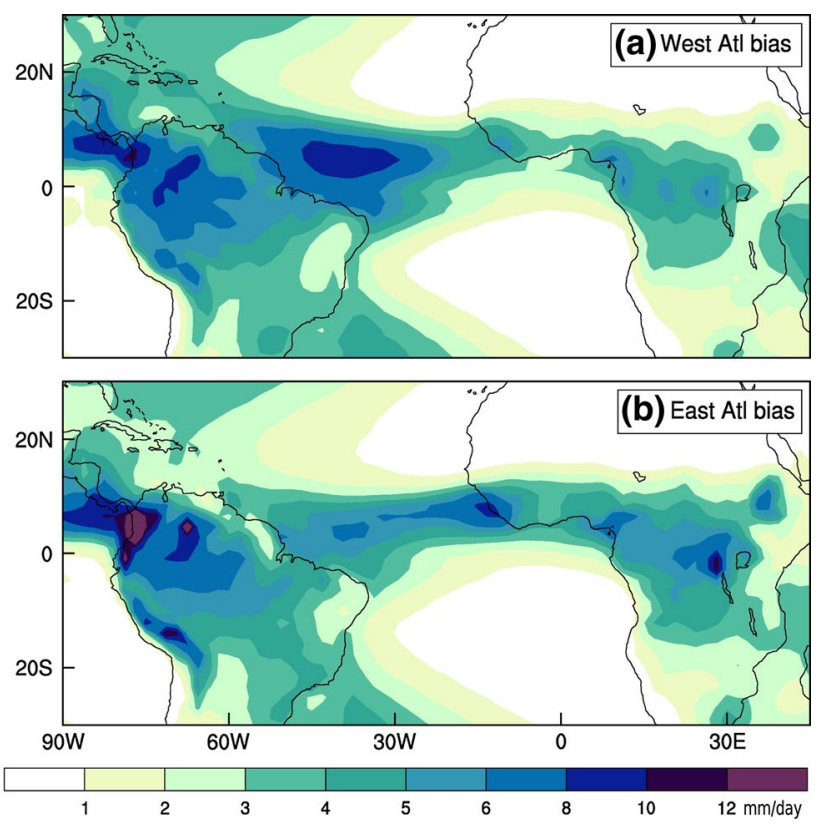

Fig. 4 Mean state of precipitation over the tropical Atlantic for models with a West Atlantic bias and b East Atlantic bias

Given the MPI-LR and GFDL-C180 object distribution, Fig. 3 summarizes the behavior of all models in terms of the longitude of the ocean object plotted against the intensity-area ratio of the land objects. This ratio is high when intense precipitation is concentrated over small areas. Models with land objects like GFDL-C180 have high intensity-area ratios. The low-ratio models, on the other hand, systematically place the ocean object westward, as seen in MPI-LR. The lower left and upper right circles in Fig. 3 indicate the model separation to West Atlantic class (low ratio, westward ocean object) and East Atlantic class (high ratio, eastward ocean object). None of the models 

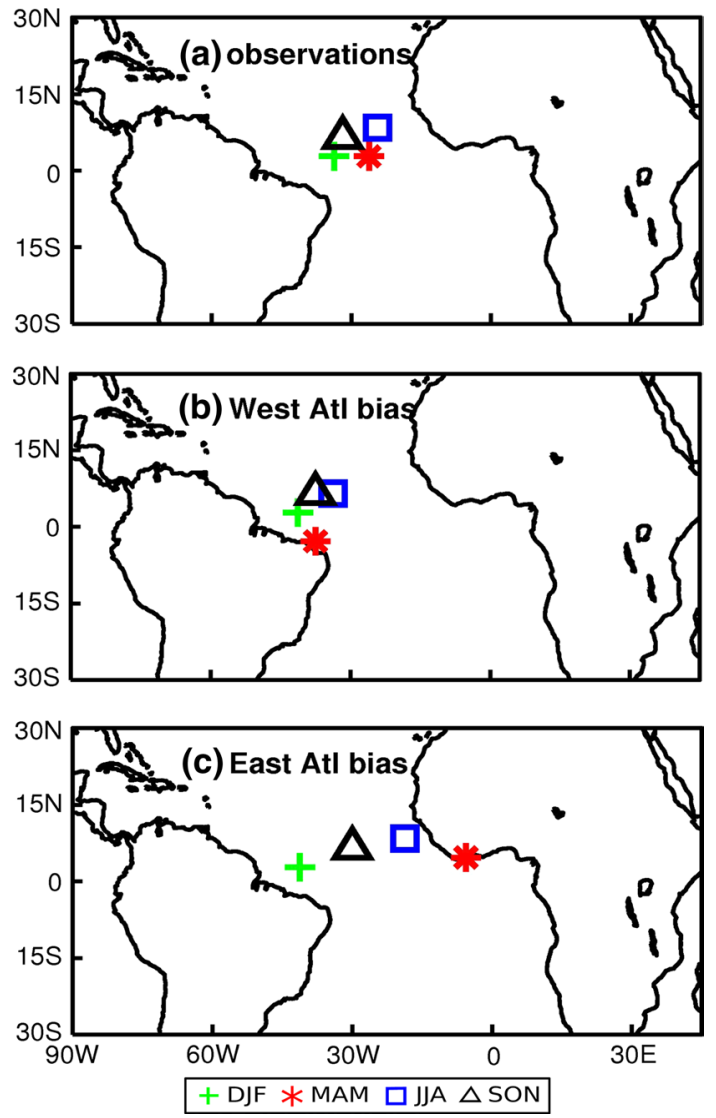

Fig. 5 Seasonal progression of the main ocean precipitation object for the ensemble mean of a observations (GPCP and TRMM, averaged), b West Atlantic bias class, and $\mathbf{c}$ East Atlantic bias class

can reproduce the observations and the biases appear larger than the observed yearly variability in the object properties as given by the interquartile range.

Figure 4 shows the mean state behavior of the ensemble of these two groups. The models have a similar precipitation structure over land, except that East Atlantic models (GFDL-C180) have intense precipitation values over orographic regions. Over ocean, even though SST is prescribed, the models show two different oceanic precipitation structures. The West Atlantic class (MPI-LR) has an ITCZ structure which appears as a dense blob of precipitation in the western part of the Atlantic basin. The East Atlantic class (GFDL-C180) has a much more longitudinal structure but rains more in the eastern than in the central part of the basin. Both model types miss the central Atlantic placement of the observed ITCZ maximum in the mean state. Some East Atlantic models have ocean objects near the central Atlantic (FGOALS, CESM, CAN-AM, CNRM, CCSM). This is a consequence of their more longitudinally distributed ITCZ structure being clustered as one contiguous region. While these models still rain more in the eastern than in the central Atlantic, they have a weaker bias compared to other models like GFDL-C180.

\subsection{The seasonal cycle}

The mean state of precipitation in the models is influenced by how well they simulate the seasonal cycle. The relationship of mean state biases with the seasonal cycle of precipitation is explored by again performing an object-based analysis.

Figure 5 shows the seasonal evolution of the Atlantic marine ITCZ, as represented by the migration of the main ocean object per season. Observations (GPCP and TRMM averaged) show a central Atlantic placement of the precipitation object through all seasons, most markedly so in March-April-May (MAM). The West Atlantic bias is apparent with Fig. 5b showing a consistent westward placement of the ocean object for all four seasons. Figure 5c, representing models with the East Atlantic bias, shows a more longitudinally extended progression of the precipitation object following the seasonal cycle. During boreal fall and winter, the models and observations all show objects located in the western part of the basin. It is during spring that the two model groups begin to deviate from each other and from the observations. The models place the objects on opposite sides of the Atlantic with respect to the observations. Models with the East Atlantic bias place the main spring object at the Gulf of Guinea in West Africa. They have a secondary object located near the coast of Brazil (not shown), indicative of a tilted ITCZ structure in MAM (Richter and Xie 2008).

Previous studies have shown that the precipitation structure in MAM is a determining factor for the evolution of SST and surface winds during the next seasons in coupled simulations (DeWitt 2005; Richter and Xie 2008; Richter et al. 2013; Zermeno-Diaz and Zhang 2013). Such studies often used an ensemble mean of models to highlight differences between observed and modeled precipitation distributions, which can give a distorted view in the presence of two model clusters. Figure 6 shows the structure of precipitation anomaly when the ensembling takes into account the two classifications of models. During MAM, a southward shift of the ITCZ with a maximum over the coast of Brazil is apparent for models with the West Atlantic bias. This southward shift is also present in models with the East Atlantic bias, though it is less pronounced and is further accompanied by excessive precipitation over the Gulf of Guinea. Excessive precipitation over the Gulf of Guinea and deficient precipitation west of this region, akin to Fig. 6b, has already been noted by Richter and Xie (2008). They argued that it is this eastwest precipitation bias in AMIP models which drives an 
Fig. 6 Precipitation anomaly (model minus GPCP observation) in MAM (a, b) and JJA (c, d) for models with the West Atlantic bias (a, c) and with the East Atlantic bias (b, d). Red boxes are used for the conceptual diagram in Fig. 9
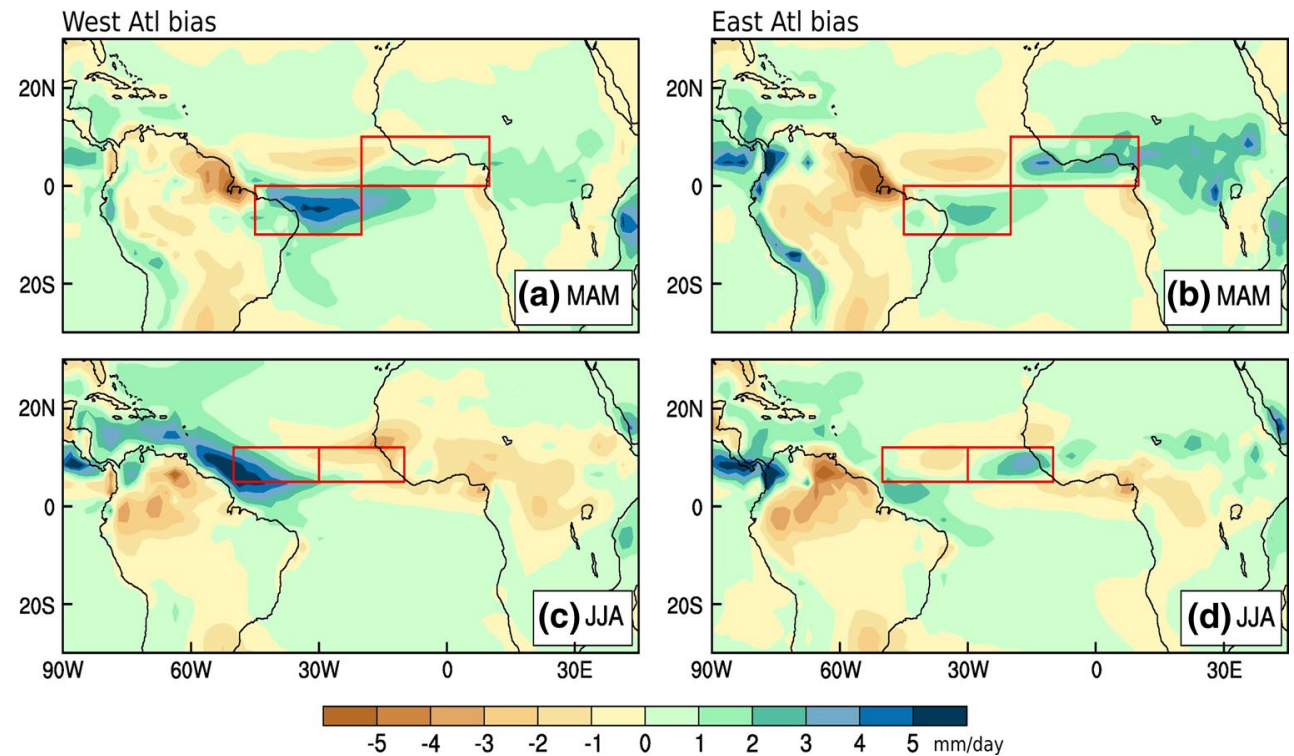

anomalous westerly flow, causing a reversed SST gradient in coupled simulations. In a later paper, Richter et al. (2013) however proposed that it is the southward shift of the ITCZ in the models, a situation more akin to Fig. 6a, which leads to the westerly wind error by inhibiting southeasterlies from crossing the equator. While both the southward shift of the ITCZ and the excessive precipitation over the Gulf of Guinea during MAM will induce wind anomalies, it is unclear which one is actually responsible for the westerly wind error. But whether models rain more over the eastern or western coast in boreal spring is largely dependent on the models included in the ensemble. By distinguishing models with West Atlantic bias from those with East Atlantic bias and performing an ensemble mean for each group, one could see a clearer separation of the precipitation bias from one coast to the other.

During MAM, the East Atlantic models also have, in general, a wetter Sahel and Congo region than West Atlantic models. Over the Amazonia, both model classes have deficient precipitation, especially over the northeastern border (Amapa and Guiana regions). In JuneJuly-August (JJA), both models have a dry Amazonia but East Atlantic models have a wetter Sahel (Fig. 6c, d). Noteworthy are especially the differences over the Atlantic ocean, in agreement with Fig. 5. Models with the West Atlantic bias show excessive precipitation along the coast of Brazil and deficient precipitation in the eastern basin. Models with the East Atlantic bias show excessive precipitation in a localized region along the coast of West Africa (Guinea Bissau and Senegal), accompanied by deficient precipitation west of this region. The anomaly structure in JJA is maintained in boreal fall. During boreal winter, the two classes both have excessive rain in
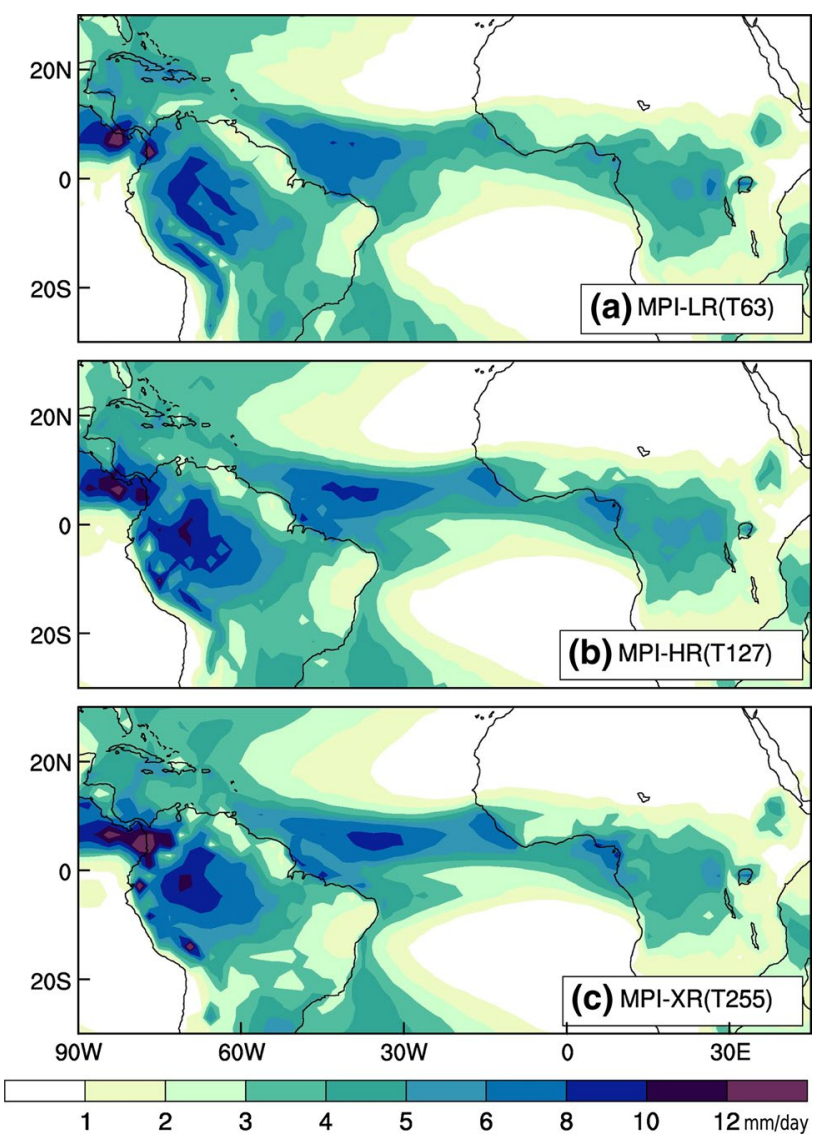

Fig. 7 Mean state ITCZ structure in different resolutions of the MPI model: a LR-T63, b HR-T127, and c XR-T255

the west and deficient rain in the east, but West Atlantic models rain more in the western basin than East Atlantic models (not shown). 
Fig. 8 Mean large-scale circulation during boreal spring for low (top panel) versions of two models, $\mathbf{a}$ MPI and $\mathbf{b}$ GFDL. The vectors show the horizontal wind at $850 \mathrm{hPa}$ and the shadings represent the vertical velocity at $500 \mathrm{hPa}$, green is for upward motion and red for subsidence. The bottom panel shows the horizontal wind difference (vectors) and vertical velocity difference (shading) between the high and low resolution versions of $\mathbf{c}$ MPI and $\mathbf{d}$ GFDL
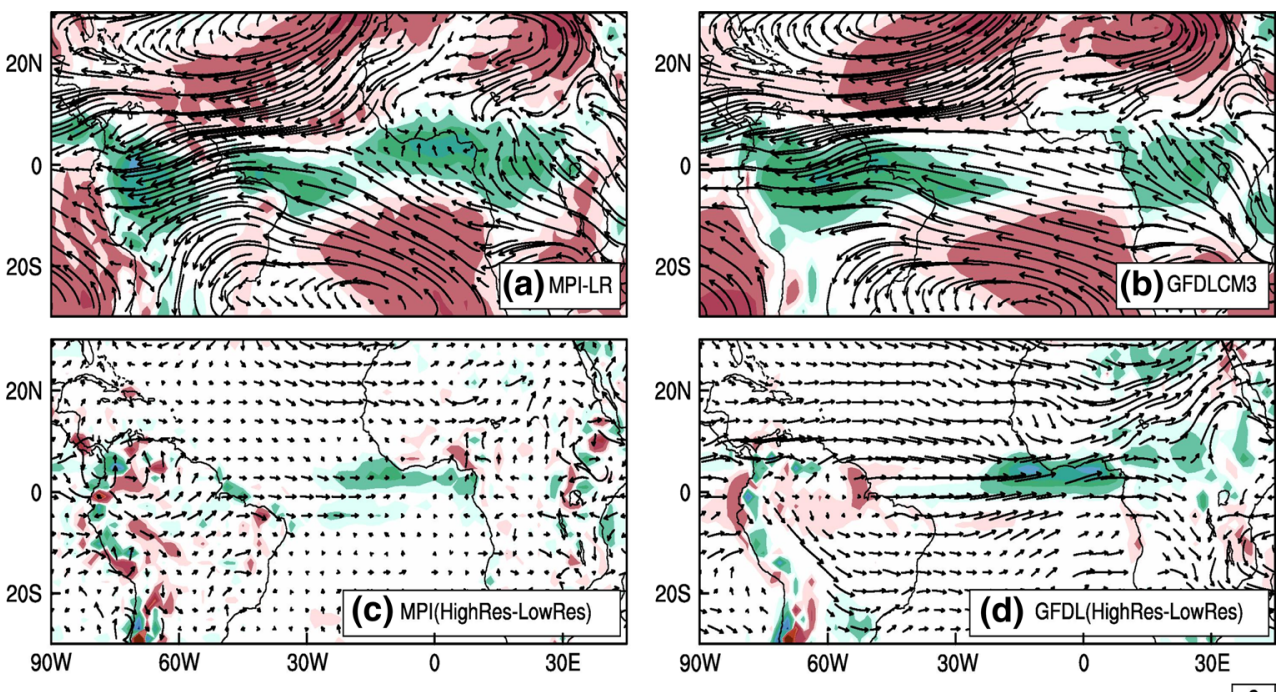

$90 \mathrm{~W}$
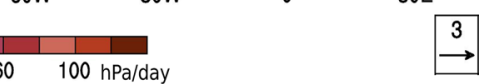

\section{Controls on the Atlantic marine ITCZ structure}

With a wide range of parameters which could change from one model to another, it is not obvious why the set of models considered in this study separate into two clusters. Looking at Table 1, the model classification seems to follow a trend based on horizontal resolution. There is a tendency for the East Atlantic class to have more gridpoints along the longitude while most models with the West Atlantic bias have less gridpoints. A detailed consideration of the model MPI indeed indicates a dependence of the ITCZ structure on horizontal resolution as illustrated in Fig. 7. A reduction in the West Atlantic bias is apparent as the resolution is increased from T63 to T255 and a structure closer to observations is attained. Specifically, the precipitation maximum over ocean shifts towards the central Atlantic with higher resolution. The decrease in precipitation near the coast of Brazil is accompanied by an increase in precipitation near the coastal regions of West Africa. The improvement is not as apparent in the African continent, where the precipitation distribution does not change significantly when the resolution is increased. Over South America, the structure does not change except that the high resolution runs tend to show intense precipitation values over the Andes and Guiana highland regions. That MPI-HR and XR remain under the West Atlantic class is a consequence of the object-identification algorithm which still places the ocean object a little to the west of the observed object.

Figure 8 shows the circulation in MAM (the season when the two classes start to diverge) using the MPI and GFDL models with their low and high resolution versions. Although their low resolution versions exhibit a distinct pattern, especially in vertical velocity, increasing the resolution yields similar effects. Both models show that an

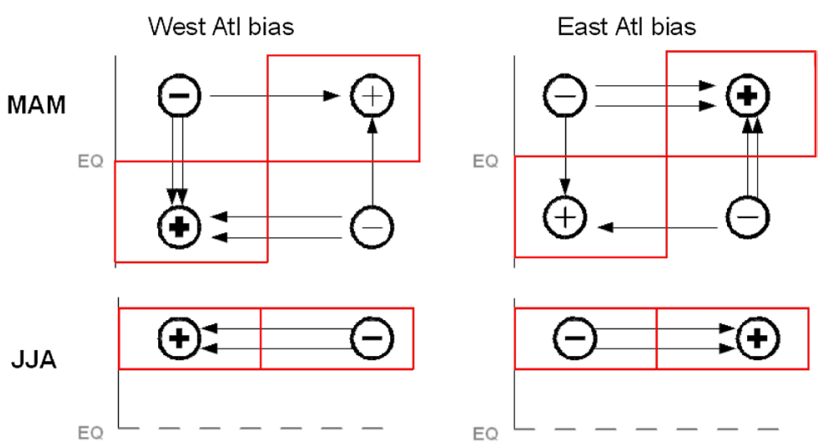

Fig. 9 Simplified sketch of the circulation during MAM and JJA for the two types of models. A plus indicates overestimation of precipitation with respect to GPCP observations while a minus indicates underestimation. The thickness of the signs is proportional to the magnitude of the bias. The arrows illustrate the low-level zonal wind associated with the precipitation biases. The mean flow along the equator is easterly. The location of the red boxes is the same as in Fig. 6

increase in horizontal resolution leads to increased rainfall over the Gulf of Guinea, accompanied by stronger upward motion over this region. The enhanced convergence is associated with stronger low-level $(850 \mathrm{hPa})$ westerlies which, on one hand, can reinforce the anomalous deep convection along the coast. On the other hand, it also suppresses some of the precipitation that would otherwise have fallen over the Brazil coast. This results in a more eastward placement of the ocean precipitation object.

Precipitation over the Gulf of Guinea in spring is crucial in determining the ITCZ structure during summer. The full loop is schematically illustrated in Fig. 9. The boxes in MAM indicate the location of the west and east coastal bias of the models. The boxes in JJA mark the observed location of the ITCZ, split into an eastern and western part at 
Fig. 10 Boreal spring (a, b) and summer (c, d) SST (shaded) and precipitation (contours, interval is $4 \mathrm{~mm} /$ day starting at $2 \mathrm{~mm} /$ day) of West Atlantic (a, c) and East Atlantic class $(\mathbf{b}, \mathbf{d})$

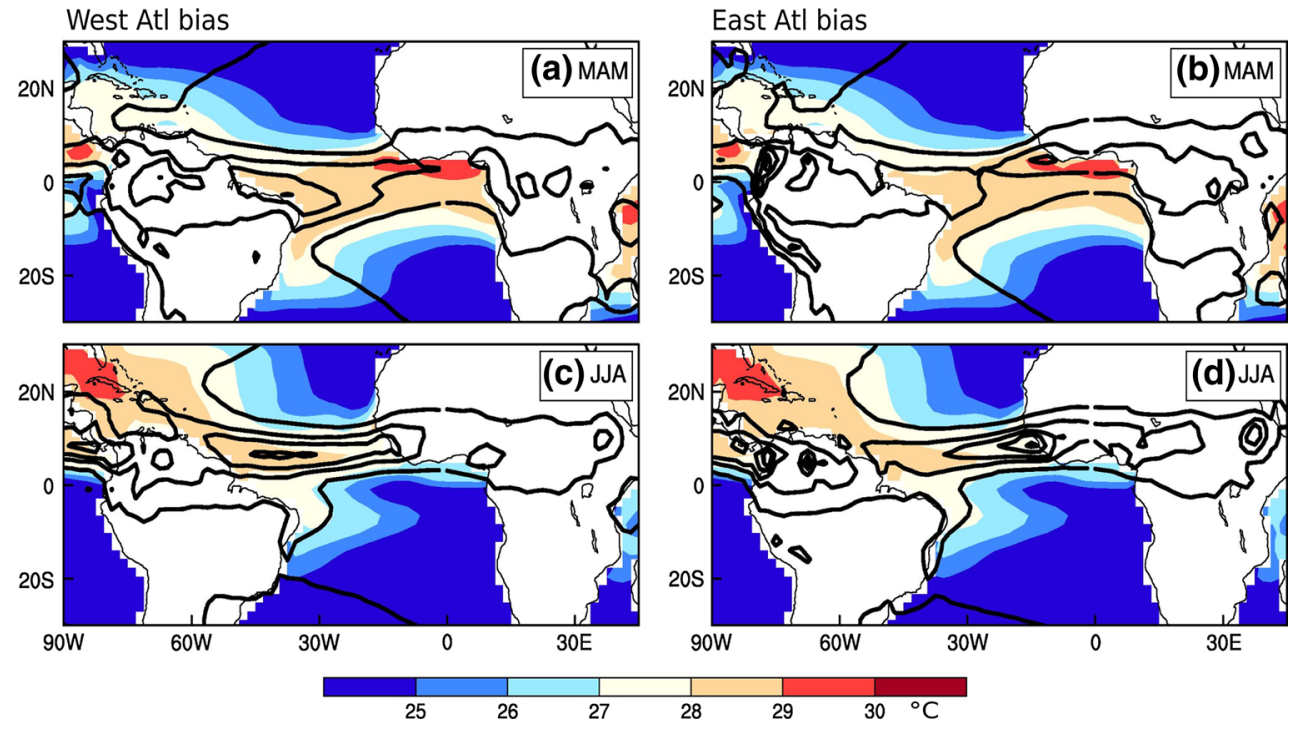

$30^{\circ} \mathrm{W}$ (central Atlantic). Similar boxes are shown in Fig. 6 for reference. In MAM, the two model groups differ in the strength of convection from one coast to the other, as shown by the prominence of the symbols. The East Atlantic class rains more over the Gulf of Guinea and as the ITCZ moves northwards in JJA, these models continue to rain in the east. The West Atlantic class rains more over the coast of Brazil in MAM and continues to rain in the western basin during JJA. Note that in both model classes, the boreal summer season replicates the location of the precipitation maximum during spring. The east-west partitioning of precipitation in spring is carried over to the summer, and explains the two different Atlantic ITCZ structures in the mean state.

The previous explanation stresses the importance of the east-west partitioning of precipitation over the ocean and relates it to the effect of resolution. However, other factors may play a role. As Richter and Xie (2008) suggested, a small ocean basin like the Atlantic is strongly influenced by convection from the adjacent continents. Richter et al. (2012) emphasized the role of the precipitation deficit over Amazon and excess over Congo in controlling the circulation over the Atlantic. In particular, they suggested that increased convection over Amazon leads to stronger easterlies. If so, West Atlantic models with stronger easterlies than East Atlantic models (see Fig. 8) should have more Amazonian precipitation. However, this seems not to be the case with models investigated in this study as both model classes show a dry bias over Amazon in spring and summer (see Fig. 6). This is also supported by the study of Wahl et al. (2011) with one version of the Kiel Climate Model, where they demonstrated that stronger easterlies and a reduced SST bias emerge when there is more precipitation over the coast of Brazil, even though a dry bias persists over the Amazonia. With a tercile difference ensemble approach,
Zermeno-Diaz and Zhang (2013) also found no relation with Amazon rainfall deficit and wind errors during MAM. They noted instead a rainfall excess over the coast of Brazil. The atmospheric origin of the westerly wind problem may not be an issue of continent-to-continent precipitation biases alone but of how models represent the ITCZ structure from one coast to the other as well.

An alternative hypothesis for the West Atlantic bias would be the effect of the adjacent South American orography on the large-scale circulation. It is plausible that models with the East Atlantic bias capture the South American circulation better, do not rain excessively over the coast of Brazil, and can still rain over the Gulf of Guinea. However, a regime-sorting analysis on deep convection over northern regions of South America versus deep convection over the coast of Brazil does not show a clear connection between the two. The peaked precipitation behavior of the East Atlantic class, mostly occurring in the Andes, is likely a consequence of high resolution rather than a cause for the suppression of the West Atlantic bias. This further strengthens our hypothesis that it is horizontal resolution which appears to have the largest influence on the marine ITCZ structure through its influence on coastal precipitation along the equatorial Atlantic.

Biasutti et al. (2006) proposed that models collocate SST and precipitation too strongly, thus causing the southward shift of the ITCZ (near the coast of Brazil) during boreal spring. The present analysis does not support this SSTprecipitation maxima hypothesis (see Fig. 10). In spring, the West Atlantic class rains excessively over the western basin even though the SST maximum is located on the eastern coast, at the Gulf of Guinea. While the precipitation maximum in the East Atlantic class is indeed at the Gulf of Guinea during spring, it remains in the eastern basin during summer, even though the SST maximum has shifted to 
the west. Neither the West nor East Atlantic model classes show a clear connection between the seasonal evolution of the SST maximum and precipitation maximum over the tropical Atlantic ocean.

Another player could be the convection scheme. Table 1 indicates no obvious relationship between the model classification and the convective parameterization. It is difficult to see a systematic behavior, given that models with the same convection scheme fall into separate model clusters. The three versions of the MPI model, with different resolutions but same convective parameterization, indicate a reduction of the West Atlantic bias with increasing resolution. Even if convection is turned off, the low resolution MPILR still exhibits the West Atlantic bias. Furthermore, if the call to the deep convection scheme is inhibited and most of the convection is explicit, as in the case with GFDL-C180 (Zhao et al. 2009), the East Atlantic bias persists. However, the convection scheme may influence the resolution limit at which a particular model transitions from a West Atlantic bias to an East Atlantic bias. For instance, the GFDL model shows a transition from West to East Atlantic bias when the resolution is increased four times (see Table 1). On the other hand, with the same increase in resolution, the MPI model does not show a full transition to the East Atlantic bias.

It should be noted that the tropical Atlantic basin is flanked by two land masses less than 3,000 km apart, with more African land mass north of the equator and more South American land mass south of the equator. Perhaps it is this relatively small distance between the two continents, combined with their asymmetric distribution near the equator, which makes the representation of the marine ITCZ structure particularly sensitive to coastal precipitation and to how well these coastlines are captured by a model. In fact, Schiemann et al. (2013) attributed the reduction in dry precipitation bias over the Maritime continent at higher horizontal resolution to better resolved land fraction and increased latent heat flux over coastal areas. The geometry of the tropical Atlantic is such that biases in coastal precipitation can significantly affect the overall marine ITCZ structure in the seasonal cycle and consequently, the mean state. The topography might also play a role, especially in north Africa whose orographic features influence the circulation and precipitation patterns in Sahel. Indeed Fig. 8 shows stronger westerlies over north Africa for high resolution. These ideas must be explored further through sensitivity analyses.

Coupling with the ocean introduces more complexities. For instance, Patricola et al. (2012) found that the relationship between wind, SST, and precipitation is dependent on the spatial resolution of the ocean model used. It would be very interesting to investigate whether the relationships uncovered in this study remain apparent in coupled simulations, a topic for future studies.

\section{Conclusions}

This study investigated the tropical Atlantic precipitation distribution in 24 atmosphere-only models. An object-based analysis patterned after Wernli et al. (2008) was employed in order to condense the original precipitation field to areas of interest called precipitation objects. By performing such an analysis for the mean precipitation state, two classes of model behavior were found. Class 1 models place the ocean precipitation object in the west basin, whereas it is in the central Atlantic in observations. These are the models with the West Atlantic bias. Class 2 models rain excessively over orographic regions, showing peaked land objects. The oceanic precipitation in class 2 models is more longitudinally distributed like in the observations, but these models rain more in the eastern basin than in the central Atlantic, showing the East Atlantic bias. The emergence of the two model classes are difficult to explain on the basis of the hypothesis of Biasutti et al. (2006), which says that model biases reflect a too strong coupling of convection to underlying SSTs.

Focusing on the marine ITCZ, the model classification in the mean state of precipitation is traced to a separation already present in the seasonal cycle. In boreal spring, the two classes of models place the ocean object on opposite coasts: south Brazil coast and Gulf of Guinea. In the succeeding boreal summer season, as the ITCZ moves northwards, the two classes maintain this west-east partitioning of precipitation. West Atlantic models continue to have their peak in precipitation over the coast of Brazil while East Atlantic models rain north of the Gulf of Guinea. The higher boreal spring precipitation over the Gulf of Guinea in East Atlantic models is found to be sensitive to horizontal resolution in the two models studied here. Models with high horizontal resolution show stronger deep convection over the Gulf of Guinea and stronger westerlies, suppressing precipitation in Brazil. Hence, the difference by which East and West Atlantic bias models represent coastal precipitation in the seasonal cycle results in the two different marine ITCZ structures.

The present study concludes that (1) the Atlantic ITCZ structure in the models is strongly influenced by the seasonal cycle of precipitation along the coasts of Brazil and Gulf of Guinea, (2) the coast-to-coast precipitation in boreal spring influences the east-west partitioning of precipitation in summer, and (3) horizontal resolution influences the weight of precipitation bias from one coast to the other.

Acknowledgments The research leading to these results has received funding from the European Union, Seventh Framework Programme (FP7/20072013) under Grant agreement 244067 to the EUCLIPSE Project. The authors thank Elisa Manzini, Christina Patricola, and an anonymous reviewer for valuable comments that have helped improve the manuscript. 
Open Access This article is distributed under the terms of the Creative Commons Attribution License which permits any use, distribution, and reproduction in any medium, provided the original author(s) and the source are credited.

\section{References}

Adler R, Huffman G, Chang A, Ferraro R, Xie P, Janowiak J, Rudolf B, Schneider U, Curtis S, Bolvin D, Gruber A, Susskind J, Arkin $P$ (2003) The version 2 global precipitation climatology project (GPCP) monthly precipitation analysis (1979-present). J Hydrometeor 4:1147-1167

Andersson A, Fennig K, Klepp C, Bakan S, Grassl H, Schulz J (2010) The Hamburg ocean atmosphere parameters and fluxes from satellite data-HOAPS-3. Earth Syst Sci Data 2:215-234

Betts A, Miller M (1986) A new convective adjustment scheme. Part II: single column tests using GATE wave, BOMEX, ATEX and arctic air-mass data sets. Q J R Meteorol Soc 112:693-709

Biasutti M, Sobel A, Kushnir Y (2006) AGCM precipitation biases in the Tropical Atlantic. J Clim 19:935-957

Bony S, Emanuel K (2001) A parameterization of the cloudiness associated with cumulus convection: evaluation using TOGA COARE data. J Atmos Sci 58:3158-3183

Bougeault P (1985) A simple parameterization of the large-scale effects of cumulus convection. Mon Wea Rev 113:2108-2121

Bretherton C, McCaa J, Grenier H (2004) A new parameterization for shallow cumulus convection and its application to marine subtropical cloud-topped boundary layers. Part I: description and 1D results. Mon Weather Rev 132:864-882

Chang C, Carton J, Grodsky S, Nigam S (2007) Seasonal climate of the tropical Atlantic sector in the NCAR community climate system model 3: error structure and probable causes of errors. J Clim 20:1053-1070

Chang C, Nigam S, Carton J (2008) Origin of the springtime westerly bias in equatorial Atlantic surface winds in the community atmosphere model version 3 (CAM3) simulation. J Clim 21:4766-4778

Chikira M, Sugiyama M (2010) A cumulus parameterization with state-dependent entrainment rate. Part I: description and sensitivity to temperature and humidity profiles. J Atmos Sci 67:2171-2193

Cook K, Hsieh J, Hagos S (2004) The Africa-South America intercontinental teleconnection. J Clim 17:2851-2865

Davey M, Huddleston M, Sperber K et al (2002) STOIC: a study of coupled model climatology and variability in the tropical ocean regions. Clim Dyn 18:403-420

Davis C, Brown B, Bullock R (2006) Object-based verification of precipitation forecasts. Part I: methodology and application to mesoscale rain areas. Mon Weather Rev 134:1772-1784

DeWitt D (2005) Diagnosis of the tropical Atlantic near-equatorial SST bias in a directly coupled atmosphere-ocean general circulation model. Geophys Res Lett 32

Del Genio A, Yao M, Jonas J (2007) Will moist convection be stronger in a warmer climate? Geophys Res Lett 34(16):L16703

Donner L (1993) A cumulus parameterization including mass fluxes, vertical momentum dynamics, and mesoscale effects. J Atmos Sci 50:889-906

Ebert E, Gallus W (2009) Toward better understanding of the contiguous rain area (CRA) method for spatial forecast verification. Weather Forecast 24:1401-1415

Ebert E, McBride J (2000) Verification of precipitation in weather systems: determination of systematic errors. J Hydrol 239:179-202

Emanuel K (1991) A scheme for representing cumulus convection in large-scale models. J Atmos Sci 48:2313-2335
Fritsch J, Chappell C (1980) Numerical prediction of convectively driven mesoscale pressure systems. Part I : cumulus parametrization. J Atmos Sci 37:1722-1733

Gates WL (1992) Amip: the atmospheric model intercomparison project. Bull Am Meteor Soc 73:1962-1970

Gilleland E, Ahijevych D, Brown B, Casati B, Ebert E (2009) Intercomparison of spatial forecast verication methods. Weather Forecast 24:1416-1430

Gregory D (2001) Estimation of entrainment rate in simple models of convective clouds. Q J R Meteorol Soc 127:53-72

Gregory D, Rowntree P (1990) A mass flux convection scheme with representation of cloud ensemble characteristics and stability dependent closure. Mon Weather Rev 118:1483-1506

Hagos S, Cook K (2005) Influence of surface processes over Africa on the Atlantic marine ITCZ and South American precipitation. J Clim 18:4993-5010

Hohenegger C, Stevens B (2013) Controls on and impacts of the diurnal cycle of deep convective precipitation. J Adv Model Earth Syst 4:801-815

Huffman G, Adler R, Bolvin D, Gu G, Nelkin E, Bowman K, Hong Y, Stocker E, Wolff D (2007) The TRMM multi-satellite precipitation analysis: quasi-global, multi-year, combined-sensor precipitation estimates at fine scale. J Hydrol 8:38-55

Mitchell TP, Wallace JM (1992) The annual cycle in equatorial convection and sea surface temperature. J Clim 5:1140-1156

Nordeng T (1994) Extended versions of the convection parametrization scheme at ECMWF and their impact upon the mean climate and transient activity of the model in the tropics. Research Dept Technical Memorandum No 206, ECMWF, Shinfield Park, Reading RG2 9AX, United Kingdom

Okumura Y, Xie S (2004) Interaction of the equatorial cold tongue and the African monsoon. J Clim 17:3589-3602

Patricola C, Li M, Xu Z, Chang P, Saravanan R, Hsieh J (2012) An invesitgation of tropical Atlantic bias in a high-resolution coupled regional climate model. Clim Dyn 39:2443-2463

Richter I, Xie S (2008) On the origin of equatorial Atlantic biases in coupled general circulation models. Clim Dyn 31: $587-598$

Richter I, Xie S, Wittenberg A, Masumoto Y (2012) Tropical Atlantic biases and their relation to surface wind stress and terrestrial precipitation. Clim Dyn 38:985-1001

Richter I, Xie S, Doi T, Masumoto Y (2013) Equatorial Atlantic variability and its relation to mean state biases in CMIP5. Clim Dyn 42:171-188

Schiemann R, Demory M, Mizielinski M, Roberts M, Shaffrey L, Strachan J, Vidale P (2013) The sensitivity of the tropical circulation and maritime continent precipitation to climate model resolution. Clim Dyn. doi:10.1007/s00382-013-1997-0

Stevens B, Duan J, McWilliams J, Muennich M, Neelin J (2002) Entrainment, Rayleigh friction, and boundary layer winds over the tropical Pacific. J Clim 15:30-44

Stevens B, Giorgetta M, Esch M, Mauritsen T, Crueger T, Rast S, Salzmann M, Schmidt H, Bader J, Block K, Brokopf R, Fast I, Kinne S, Kornblueh L, Lohmann U, Pincus R, Reichler T, Roeckner E (2013) Atmospheric component of the MPI-M earth system model: ECHAM6. J Adv Model Earth Syst 5:146-172

Stockdale T, Balmaseda M, Vidard A (2006) Tropical Atlantic SST prediction with coupled ocean-atmosphere GCMs. J Clim 19:6047-6061

Sultan B, Janicot S (2003) The west African monsoon dynamics. Part II: The "preonset" and "onset" of the summer monsoon. J Clim $16: 3407-3427$

Tiedtke M (1989) A comprehensive mass flux scheme for cumulus parametrization in large-scale models. Mon Weather Rev 117:1779-1800 
Wahl S, Latif M, Park W, Keenlyside N (2011) On the Tropical Atlantic SST warm bias in the Kiel Climate Model. Clim Dyn 36:891-906

Wernli H, Paulat M, Hagen M, Frei C (2008) SAL-A novel quality measure for the verification of quantitative precipitation forecasts. Mon Weather Rev 136:4470-4487

Wilcox E, Donner L (2007) The frequency of extreme rain events in satellite rain- rate estimates and an atmospheric general circulation model. J Clim 20:53-69

Yin L, Fu R, Shevliakova E, Dickson R (2012) How well can CMIP5 simulate precipitation and its controlling processes over tropical South America? Clim Dyn 41:3127-3143

Yukimoto S, Yoshimura H, Hosaka M, Sakami T, Tsujino H, Hirabara M, Tanaka T, Deushi M, Obata A, Nakano H, Adachi Y, Shindo E, Yabu S, Ose T, Kitoh A (2011) Meteorological research institute earth system model version 1 (MRI- ESM1): model description. Technical report of the Meteorological Research Institute 64
Zebiak S (1993) Air-sea interaction in the equatorial Atlantic region. J Clim 6:1567-1586

Zermeno-Diaz D, Zhang C (2013) Possible root causes of surface westerly biases over the equatorial Atlantic in global climate models. J Clim 26:8154-8168

Zhang G, McFarlane N (1995) Sensitivity of climate simulations to the parameterization of cumulus convection in the Canadian Climate Centre general circulation model. Atmos Ocean 33:407-446

Zhang G, Mu M (2005) Effects of modifications to the Zhang-McFarlane convection parameterization on the simulation of the tropical precipitation in the National Center for Atmospheric Research Community Climate Model, version 3. J Geophys Res 110

Zhao M, Held I, Lin S, Vecchi G (2009) Simulations of global hurricane climatology, interannual variability, and response to global warming using a 50-km resolution GCM. J Clim 22:6653-6678 